\title{
Vegetative Compatibility Groups of Verticillium dahliae in Israel: Their Distribution and Association with Pathogenicity
}

\author{
Nadia Korolev, Jaacov Katan, and Talma Katan
}

First and third authors: Department of Plant Pathology, ARO, The Volcani Center, Bet Dagan 50250, Israel; and second author: Department of Plant Pathology and Microbiology, The Hebrew University, Rehovot 76100, Israel.

Accepted for publication 24 January 2000.

\begin{abstract}
Korolev, N., Katan, J., and Katan, T. 2000. Vegetative compatibility groups of Verticillium dahliae in Israel: Their distribution and association with pathogenicity. Phytopathology 90:529-536.

A collection of 565 isolates of Verticillium dahliae, recovered between 1992 and 1997 from 13 host plant species and soil at 47 sites in Israel, was tested for vegetative compatibility using nitrate-nonutilizing (nit) $\mathrm{mu}-$ tants. Three vegetative compatibility groups (VCGs) were found and identified as VCG2A (28 isolates), VCG2B (158 isolates), and VCG4B (378 isolates) by using international reference strains. One isolate was heterokaryon self-incompatible. Of the VCG2B isolates, $92 \%$ were recovered from the northern part of Israel and 90\% of VCG4B isolates were recovered from the south, with some overlap in the central region. Isolates of the minor

different VCGs based on colony and microsclerotial morphology, temperature responses, and, partially, pathogenicity. Different pathotypes were defined among 60 isolates tested, using cotton (cv. Acala SJ-2) and eggplant (cv. Black Beauty) as differentials. All isolates in VCG2A and $86 \%$ of the isolates in VCG4B, irrespective of their origin, induced weak to moderate symptoms on cotton and moderate to severe symptoms on eggplant and were similar to the previously described cotton nondefoliating pathotype. In contrast, all cotton isolates in VCG2B caused severe foliar symptoms, stunting, and often death, but little or no defoliation of inoculated cotton plants. These were defined as a cotton defoliating-like pathotype and induced only weak to moderate symptoms on eggplant. We concluded that vegetative compatibility grouping of $V$. dahliae in Israel is closely associated with specific pathogenicity and other phenotypic traits.
\end{abstract} group VCG2A were geographically scattered among the two major VCGs. Isolates of the same VCG resembled one another more than isolates from

Verticillium dahliae is an economically important pathogen causing vascular wilt on more than 160 plant species (24). In Israel, Verticillium wilt occurs in many regions, including important agricultural areas such as the Negev region in the south and Yizre'el Valley in the north. It inflicts serious losses in potato, cotton, and some vegetable crops $(4,17,19,29)$ and occasionally occurs on ornamentals and fruit trees. In view of its broad host range and apparently low host specificity, $V$. dahliae has been considered to have little genetic diversity. However, more recent vegetative-compatibility and molecular studies suggest that there is significant genetic diversity in V. dahliae (23).

Vegetative compatibility refers to the ability of individual fungal strains to undergo mutual hyphal anastomosis, which results in viable heterokaryons. When a heterokaryon is established, the participating isolates are placed in the same vegetative compatibility group (VCG). In $V$. dahliae, an anamorphic fungus with no known sexual stage, hyphal anastomosis and heterokaryosis are the only means of exchanging genetic information among different strains. Thus, strains belonging to the same VCG have the potential to share a common gene pool separated from the gene pools of other VCGs. Using nitrate-nonutilizing (nit) mutants, three to five VCGs have been identified among $V$. dahliae strains from diverse geographic and plant sources worldwide (10-12,23,27,28). A set of isolates and nit mutant testers was described that represents all known VCGs $(10,11,27,28)$. This set of reference strains was provided by R. C. Rowe (the Ohio Agricultural Research and Development Center [OARDC], Wooster).

In a previous study, 34 isolates of $V$. dahliae from six host plants in Israel were examined for vegetative compatibility (1). Two dis-

Corresponding author: T. Katan; E-mail address: vpptlg@volcani.agri.gov.il

Publication no. P-2000-0323-01R

(C) 2000 The American Phytopathological Society
Additional keywords: potato, tomato, Verticillium wilt.

tinct VCGs were identified among 33 isolates; the status of the remaining isolate remained unclear. Using a larger number of isolates from Israel, the objectives of the current study were to (i) determine the VCGs diversity and their relatedness to internationally recognized VCGs; and (ii) reveal any association between VCG, host plant origin, regional distribution, growth characteristics, and virulence in the population.

\section{MATERIALS AND METHODS}

Isolation of $\boldsymbol{V}$. dahliae from plants and soil. $V$. dahliae was isolated during 1992 to 1997 from cotton (Gossypium hirsutum and G. barbadense), tomato (Lycopersicon esculentum), eggplant (Solanum melongena), Chrysanthemum spp., potato (Solanum tuberosum), peanut (Arachis hypogea), pepper (Capsicum annuum), watermelon (Citrullus lanatus), weeds (Astragalus sp., Brassica sp., Senecio sp., Urtica sp., and Xanthium sp.), and soil, as previously described $(15,16)$. One monoconidial culture was prepared from each isolate and stored on Czapek-Dox agar (CDA) at 5 to $7^{\circ} \mathrm{C}$.

Generation and characterization of nit mutants. nit Mutants were generated on water agar-chlorate (WAC) medium consisting of $2 \%$ agar, $0.02 \%$ glucose, and $5 \%$ potassium chlorate (15). Mycelial plugs were placed on WAC medium at five or six points in plates $\left(9 \mathrm{~cm}\right.$ in diameter) and incubated at $24^{\circ} \mathrm{C}$. Chlorate-resistant sectors, evident after 10 to 14 days, were transferred to CDA plates ( $5 \mathrm{~cm}$ in diameter). Sectors that grew on CDA as colonies with a thin, expansive mycelium were considered nit mutants. CDA amended with sodium nitrite $(0.5 \mathrm{~g} / \mathrm{liter})$ or hypoxanthine $(0.2 \mathrm{~g} /$ liter) was used for partial phenotyping of the nit mutants (7).

Vegetative compatibility grouping. Complementation between phenotypically distinct nit mutants was tested on CDA. Generally, each plate $(5 \mathrm{~cm}$ in diameter) was inoculated with three mutants, 1 to $1.5 \mathrm{~cm}$ apart in a triangular pattern, and incubated at $24^{\circ} \mathrm{C}$. Plates were scored for prototrophic growth 14 to 28 days after inocula- 
tion. Complementation was evident by the formation of a dense, aerial growth where mycelia from two mutants had met and formed a prototrophic heterokaryon. When mutants of two different strains formed a heterokaryon, their parents were assigned to the same VCG. Each pairing was performed at least twice. Twelve reference strains $(10,23)$ were provided by R. C. Rowe (OARDC, Wooster). To compare the VCGs from Israel with the internationally recognized VCGs of $V$. dahliae, nit mutants generated from each of the reference strains were used as testers in complementation tests with nit mutants representing the local VCGs.

Effect of temperature on mycelial growth. Isolate response to temperature was determined with respect to radial growth rate on agar medium and to biomass production in liquid culture. Radial growth rate was determined at eight temperatures $\left(10\right.$ to $\left.35^{\circ} \mathrm{C}\right)$. Mycelial plugs were centrally inoculated on 9-cm-diameter CDA plates and incubated in triplicate at the various temperatures. The diameter of the growing colonies was recorded 7, 14, and 21 days after inoculation, and the area under the growth curve (AUGC) was calculated using a formula for area under disease progress curve (AUDPC) (5). Pigmentation and the quantity of aerial mycelium were visually estimated. This experiment was repeated twice. To compare biomass production, 1 million conidia were added to $250-\mathrm{ml}$ flasks containing $75 \mathrm{ml}$ of potato dextrose broth. The liquid cultures were kept still in the dark at 21,24 , or $27^{\circ} \mathrm{C}$. After 4 weeks of incubation, mycelia were harvested by filtration, lyophilized, and weighed. The experiment was run in triplicate and repeated once.

Pathogenicity tests. Pathogenicity of $V$. dahliae was determined by the root-dip method using eggplant (Solanum melongena cv. Black Beauty) and cotton (Gossypium hirsutum cv. Acala SJ-2) as differential hosts. Inoculum was prepared by macerating the contents of 14-day-old CDA cultures with $150 \mathrm{ml}$ of water for $30 \mathrm{~s}$ using a Waring blender (Waring Products, New Hartford, CT). Seedlings at the cotyledon stage were uprooted from the substrate, and their roots were washed in tap water, trimmed, and dipped in the inoculum ( 1 to $5 \times 10^{6}$ conidia per $\mathrm{ml}$ ) for $3 \mathrm{~min}$. Noninoculated control seedlings were dipped in water. Each isolate was inoculated on 15 seedlings of each host plant. Seedlings were then transplanted (five per pot) to 700-ml pots filled with Rehovot sandy soil (3.8\% clay, $0.0 \%$ silt, $96.2 \%$ sand, and $0.4 \%$ organic matter; $\mathrm{pH}$ 6.9), and maintained in a greenhouse at 24 to $27^{\circ} \mathrm{C}$ and a $12-\mathrm{h}$

TABLE 1. Isolates of Verticillium dahliae from Israel, listed by vegetative compatibility group (VCG), source, and pathogenicity

\begin{tabular}{|c|c|c|c|c|c|c|}
\hline \multirow[b]{3}{*}{$\mathrm{VCG}$} & \multirow[b]{3}{*}{ Isolate } & \multirow{2}{*}{\multicolumn{2}{|c|}{ Source }} & \multicolumn{3}{|c|}{ Pathogenicity } \\
\hline & & & & \multicolumn{2}{|c|}{$\operatorname{AUDPC}(\%)^{\mathrm{v}}$} & \multirow[b]{2}{*}{ Pathotype $^{w}$} \\
\hline & & Host & Site & Cotton & Eggplant & \\
\hline \multirow[t]{12}{*}{$2 \mathrm{~A}$} & chr9 & Chrysanthemum & Bet Alpha & $13.9 \mathrm{c}$ & $26.9 \mathrm{c}$ & $\mathrm{ND} 2$ \\
\hline & $\cot 150$ & Cotton & Gan Shmuel & $19.6 \mathrm{c}$ & $39.5 \mathrm{~b}$ & ND2 \\
\hline & ep8 & Eggplant & Kfar Azza & $10.7 \mathrm{c}$ & $41.6 \mathrm{~b}$ & ND2 \\
\hline & ep30 & Eggplant & Mishmar Ayalon & $\ldots$ & $\ldots$ & $\ldots$ \\
\hline & ep4 & Eggplant & Tamra & $6.1 \mathrm{c}$ & $40.9 \mathrm{~b}$ & ND2 \\
\hline & ep5 & Eggplant & Tamra & $10.3 \mathrm{c}$ & $42.4 \mathrm{~b}$ & $\mathrm{ND} 2$ \\
\hline & pn12 & Peanut & Nir Oz & $\ldots$ & $\ldots$ & $\ldots$ \\
\hline & $\mathrm{pt} 44.3 \mathrm{G}$ & Potato & Kerem Shalom & $12.6 \mathrm{c}$ & $29.0 \mathrm{~b}$ & ND2 \\
\hline & 7 isolates & Potato & 4 sites & $\ldots$ & $\ldots$ & $\ldots$ \\
\hline & tom 24 & Tomato & Ein Shemer & $10.8 \mathrm{c}$ & $40.4 \mathrm{~b}$ & ND2 \\
\hline & 11 isolates & Tomato & 4 sites & $\ldots$ & $\ldots$ & $\ldots$ \\
\hline & tom 1 & Tomato & Unknown & $10.0 \mathrm{c}$ & $45.7 \mathrm{~b}$ & ND2 \\
\hline Subtotal & 28 isolates & 6 hosts & 14 sites & & & \\
\hline \multirow[t]{25}{*}{$2 \mathrm{~B}$} & $\operatorname{chr} 10$ & Chrysanthemum & Bet Alpha & $1.6 \mathrm{c}$ & $0.6 \mathrm{c}$ & Avirulent \\
\hline & $\operatorname{chr} 11$ & Chrysanthemum & Bet Alpha & $33.8 \mathrm{~b}$ & $66.4 \mathrm{a}$ & DL2 \\
\hline & $\operatorname{chr} 12$ & Chrysanthemum & Bet Alpha & $9.8 \mathrm{c}$ & $59.7 \mathrm{a}$ & ND3 \\
\hline & $\operatorname{chr} 13$ & Chrysanthemum & Bet Alpha & $6.1 \mathrm{c}$ & $70.3 \mathrm{a}$ & ND3 \\
\hline & $\cot 79$ & Cotton & Dalia & $58.8 \mathrm{a}$ & $16.4 \mathrm{c}$ & DL1 \\
\hline & $\cot 17$ & Cotton & Ein Shemer & $62.9 \mathrm{a}$ & $14.2 \mathrm{c}$ & DL1 \\
\hline & $\cot 117$ & Cotton & Ein Shemer & $74.5 \mathrm{a}$ & $14.7 \mathrm{c}$ & DL1 \\
\hline & $\cot 135$ & Cotton & Ein Shemer & $60.3 \mathrm{a}$ & $18.8 \mathrm{c}$ & DL1 \\
\hline & $\cot 153$ & Cotton & Ein Shemer & $80.5 \mathrm{a}$ & $18.6 \mathrm{c}$ & DL1 \\
\hline & $\cot 202$ & Cotton & Gadot & $\ldots$ & $\ldots$ & $\ldots$ \\
\hline & $\cot 5$ & Cotton & Galed & $55.9 \mathrm{a}$ & $18.1 \mathrm{c}$ & DL1 \\
\hline & $\cot 178$ & Cotton & Galed & $62.3 \mathrm{a}$ & $20.5 \mathrm{~b}$ & DL1 \\
\hline & $\cot 2$ & Cotton & Gan Shmuel & $59.6 \mathrm{a}$ & $18.4 \mathrm{c}$ & DL1 \\
\hline & $\cot 19$ & Cotton & Gan Shmuel & $56.9 \mathrm{a}$ & $8.3 \mathrm{c}$ & DL1 \\
\hline & $\cot 20$ & Cotton & Gan Shmuel & $73.5 \mathrm{a}$ & $26.4 \mathrm{~b}$ & DL1 \\
\hline & $\cot 149$ & Cotton & Gan Shmuel & $68.4 \mathrm{a}$ & $22.7 \mathrm{~b}$ & DL1 \\
\hline & $\cot 18$ & Cotton & Kfar Hahoresh & $71.8 \mathrm{a}$ & $2.7 \mathrm{c}$ & DL1 \\
\hline & $\cot 112$ & Cotton & Kfar Hahoresh & $65.4 \mathrm{a}$ & $11.0 \mathrm{c}$ & DL1 \\
\hline & $\cot 15$ & Cotton & Ramat David & $55.9 \mathrm{a}$ & $18.6 \mathrm{c}$ & DL1 \\
\hline & $\cot 60$ & Cotton & Ramat David & $80.1 \mathrm{a}$ & $15.4 \mathrm{c}$ & DL1 \\
\hline & $\cot 62$ & Cotton & Ramat David & $73.4 \mathrm{a}$ & $23.0 \mathrm{~b}$ & DL1 \\
\hline & $\cot 63$ & Cotton & Ramat David & $65.9 \mathrm{a}$ & $16.8 \mathrm{c}$ & DL1 \\
\hline & $\cot 64$ & Cotton & Ramat David & $26.0 \mathrm{~b}$ & $6.6 \mathrm{c}$ & DL1 \\
\hline & $\cot 128$ & Cotton & Ramat David & $58.0 \mathrm{a}$ & $25.9 \mathrm{~b}$ & DL1 \\
\hline & 114 isolates & Cotton & 6 sites & $\ldots$ & $\ldots$ & $\begin{array}{c}\text { (continued on the next page) } \\
\text { (c) }\end{array}$ \\
\hline
\end{tabular}

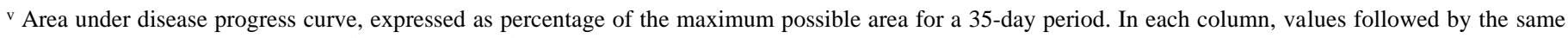
letter belong to the same cluster of mean values using the K-means clustering method. ... = Not tested.

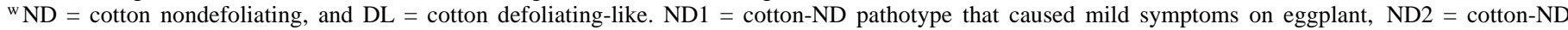
pathotype that caused moderate to strong symptoms on eggplant, and ND3 = cotton-ND pathotype that caused severe symptoms on eggplant. DL1 = cottonDL pathotype that caused mild to moderate symptoms on eggplant, and DL $2=$ cotton-DL pathotype that caused severe symptoms on eggplant.

${ }^{x}$ From potato fields.

y From cotton fields.

${ }^{\mathrm{z}}$ Heterokaryon self-incompatible. 
photoperiod for 35 days. Mean disease severity index was assessed $2,3,4$, and 5 weeks after inoculation on an arbitrary five-grade scale $(0=$ no visible symptoms, $4=$ dead plant $)$, essentially as previously described (1). A total of six greenhouse experiments was performed: 3 isolates were included in each of them as standards, and 58 additional isolates were tested one to three times. Data of experiments that did not differ significantly based on the standard isolates were combined, and AUDPCs were calculated and expressed as percentage of the maximum possible area for the 35-day periods of the experiments $(2,5)$.

Data analysis. Biomass data for the temperature experiments were subjected to two-way analysis of variance. AUGC data of the temperature experiments were subjected to analysis of covariance, using temperature as linear and quadratic covariates. Pairs of means were compared, thereafter, by contrast $t$ tests. AUDPC data of the pathogenicity experiments were subjected to the K-means clustering algorithm in order to create clusters of similar mean values. Each of the five clusters was then used to represent a pathotype, and the pathotypes were subjected to one-way analysis of variance. To compare different pathotypes, pairs of means were sub- jected to contrast $t$ tests. All tests were performed at $P=0.05$ using the Statistical Analysis System (version 6.12 or JMP 3.2.2 software, SAS Institute Inc., Cary, NC).

\section{RESULTS}

Isolates of $\boldsymbol{V}$. dahliae. A total of 565 isolates of $V$. dahliae from Israel was used in this study. Isolates were recovered from crop plants with wilt symptoms, cotton gin waste, symptomless weeds, and soil. The isolates originated from 13 host plants at 47 sites in Israel. Most of the isolates were recovered from potato (42\%) and cotton (33\%); the remainder came from eggplant, tomato, peanut, pepper, chrysanthemum, watermelon, weeds (five species), and soil (Table 1; Fig. 1); 173 isolates (mostly potato isolates from the Negev region) were obtained from $\mathrm{L}$. Tsror (Gilat experimental station).

Generation and characterization of nit mutants. WAC, a water agar-based chlorate medium developed for generating nit mutants from $V$. dahliae (15), was used. On WAC amended with 5\% chlorate, radial growth of wild-type strains was greatly restricted, and chlorate resistance appeared as sectors growing from the inoculum

TABLE 1. (continued from the preceding page)

\begin{tabular}{|c|c|c|c|c|c|c|}
\hline \multirow[b]{3}{*}{ VCG } & \multirow[b]{3}{*}{ Isolate } & \multirow{2}{*}{\multicolumn{2}{|c|}{ Source }} & \multicolumn{3}{|c|}{ Pathogenicity } \\
\hline & & & & \multicolumn{2}{|c|}{$\operatorname{AUDPC}(\%)^{\mathrm{v}}$} & \multirow[b]{2}{*}{ Pathotype $^{\mathrm{W}}$} \\
\hline & & Host & Site & Cotton & Eggplant & \\
\hline & ps1 & Cotton waste & Meitav & $\ldots$ & $\ldots$ & $\ldots$ \\
\hline & lap2 & Weed $^{\mathrm{x}}$ & Ramat David & $61.7 \mathrm{a}$ & $16.6 \mathrm{c}$ & DL1 \\
\hline & ep1 & Eggplant & Ganey Yohanan & $8.9 \mathrm{c}$ & $18.6 \mathrm{c}$ & ND1 \\
\hline & ep6 & Eggplant & Ganey Yohanan & $9.6 \mathrm{c}$ & $24.1 \mathrm{~b}$ & ND1 \\
\hline & ep7 & Eggplant & Ganey Yohanan & $10.2 \mathrm{c}$ & $21.7 \mathrm{~b}$ & ND1 \\
\hline & ep2 & Eggplant & Tamra & $3.8 \mathrm{c}$ & $55.8 \mathrm{a}$ & ND3 \\
\hline & ep3 & Eggplant & Tamra & $2.9 \mathrm{c}$ & $59.1 \mathrm{a}$ & ND3 \\
\hline & 3 isolates & Eggplant, weed & Ramat David & $\ldots$ & $\ldots$ & $\ldots$ \\
\hline & $\mathrm{s} 2$ & Pepper & Lahav & $10.6 \mathrm{c}$ & $61.0 \mathrm{a}$ & ND3 \\
\hline & 7 isolates & Pepper & Lahav & $\ldots$ & $\ldots$ & $\ldots$ \\
\hline & tom20 & Tomato & Segula & $\ldots$ & $\ldots$ & $\ldots$ \\
\hline & tom 28 & Tomato & Segula & $5.9 \mathrm{c}$ & $88.3 \mathrm{a}$ & ND3 \\
\hline Subtotal & 158 isolates & 6 hosts & 13 sites & & & \\
\hline \multirow[t]{31}{*}{$4 B$} & $\cot 24$ & Cotton & Be'ery & $16.4 \mathrm{c}$ & $36.4 \mathrm{~b}$ & ND2 \\
\hline & $\cot 25$ & Cotton & Be'ery & $9.3 \mathrm{c}$ & $34.5 b$ & ND2 \\
\hline & $\cot 26$ & Cotton & Be'ery & $4.7 \mathrm{c}$ & $31.5 \mathrm{~b}$ & ND2 \\
\hline & $\cot 13$ & Cotton & Bet Kamma & $13.9 \mathrm{c}$ & $38.4 \mathrm{~b}$ & ND2 \\
\hline & $\cot 85$ & Cotton & Bet Kamma & $10.6 \mathrm{c}$ & $43.0 \mathrm{~b}$ & ND2 \\
\hline & $\cot 129$ & Cotton & Ein Hashlosha & $9.4 \mathrm{c}$ & $35.8 \mathrm{~b}$ & ND2 \\
\hline & $\cot 133$ & Cotton & Ein Hashlosha & $7.8 \mathrm{c}$ & $46.4 \mathrm{~b}$ & ND2 \\
\hline & $\cot 92$ & Cotton & Kfar Azza & $11.4 \mathrm{c}$ & $44.8 \mathrm{~b}$ & ND2 \\
\hline & $\cot 93$ & Cotton & Kfar Azza & $11.5 \mathrm{c}$ & $49.2 \mathrm{~b}$ & ND2 \\
\hline & $\cot 94$ & Cotton & Kfar Azza & $13.2 \mathrm{c}$ & $27.3 \mathrm{~b}$ & ND2 \\
\hline & 52 isolates & Cotton & 5 sites & $\ldots$ & $\ldots$ & $\ldots$ \\
\hline & $\cot 12$ & Cotton & Re'im & $45.2 \mathrm{~b}$ & $43.6 \mathrm{~b}$ & DL2 \\
\hline & $\cot 22$ & Cotton & Zorrah & $56.3 \mathrm{a}$ & $52.4 \mathrm{a}$ & DL2 \\
\hline & $\cot 23$ & Cotton & Zorrah & $57.5 \mathrm{a}$ & $61.9 \mathrm{a}$ & DL2 \\
\hline & ep11 & Eggplant & Kfar Azza & $7.5 \mathrm{c}$ & $30.4 \mathrm{~b}$ & ND2 \\
\hline & ep12 & Eggplant & Kfar Azza & $9.4 \mathrm{c}$ & $29.5 \mathrm{~b}$ & ND2 \\
\hline & 18 isolates & Eggplant & 4 sites & $\ldots$ & $\ldots$ & $\ldots$ \\
\hline & s2.1 & Pepper & Lahav & $8.3 \mathrm{c}$ & $31.7 \mathrm{~b}$ & ND2 \\
\hline & s 2.2 & Pepper & Lahav & $5.3 \mathrm{c}$ & $26.3 \mathrm{~b}$ & ND2 \\
\hline & 9 isolates & Peanut & Nir Oz, Re'im & $\ldots$ & $\ldots$ & $\ldots$ \\
\hline & pn6 & Peanut & Re'im & $15.7 \mathrm{c}$ & $32.1 \mathrm{~b}$ & ND2 \\
\hline & pt15 & Potato & Re'im & $15.9 \mathrm{c}$ & $29.3 \mathrm{~b}$ & ND2 \\
\hline & pt21 & Potato & Re'im & $19.1 \mathrm{c}$ & $45.9 \mathrm{~b}$ & ND2 \\
\hline & pt26 & Potato & Re'im & $13.5 \mathrm{c}$ & $34.9 \mathrm{~b}$ & ND2 \\
\hline & 232 isolates & Potato & 27 sites & $\ldots$ & $\ldots$ & $\ldots$ \\
\hline & tom5 & Tomato & Ohad & $8.8 \mathrm{c}$ & $32.7 \mathrm{~b}$ & ND2 \\
\hline & 16 isolates & Tomato & 3 sites & $\ldots$ & $\ldots$ & $\ldots$ \\
\hline & wm1 & Watermelon & Unknown & $\ldots$ & $\ldots$ & $\ldots$ \\
\hline & 6 isolates & Weeds $^{\mathrm{x}}$ & 3 sites & $\ldots$ & $\ldots$ & $\ldots$ \\
\hline & 15 isolates & Soil $^{\mathrm{y}}$ & Be'ery & $\ldots$ & $\ldots$ & $\ldots$ \\
\hline & 7 isolates & Soil $^{\mathrm{x}}$ & Nir Oz & $\ldots$ & $\ldots$ & $\ldots$ \\
\hline Subtotal & 378 isolates & 12 hosts & 35 sites & & & \\
\hline $\mathrm{HSI}^{\mathrm{z}}$ & tom $2 \mathrm{G}$ & Tomato & Segula & $\cdots$ & $\cdots$ & $\cdots$ \\
\hline Total & 565 isolates & & & & & \\
\hline
\end{tabular}


plugs or as fanlike sectors at the colony perimeter. Only sectors that grew on CDA as expansive colonies with a thin mycelium were considered nit mutants. Of the examined chlorate-resistant sectors, 80 to $100 \%$ were nit mutants, and at least one nit mutant was recovered from each of the $565 \mathrm{~V}$. dahliae isolates. A total of about 2,000 nit mutants was recovered and phenotypes were determined. Most mutants grew profusely (similar to wild type) on CDA with nitrite or hypoxanthine and were accordingly classified as nitl. Some $(6 \%)$ of the nit mutants produced expansive thin mycelium on CDA with hypoxanthine and were classified as NitM. A few mutants grew very slowly on nitrite or developed moderately dense rather than expansive thin mycelium on this medium. Such mutants grew as expansive thin colonies on CDA and complemented NitM but not normal nit1 mutants and were, therefore, considered nitl. No nit3 mutants could be recognized.

In 564 out of the 565 isolates, complementary heterokaryons formed between different mutant phenotypes (nit1 and NitM) derived from the same or different parental strains. One isolate was self-incompatible. Between three and five complementation groups were found among NitM mutants within each of the local VCGs.

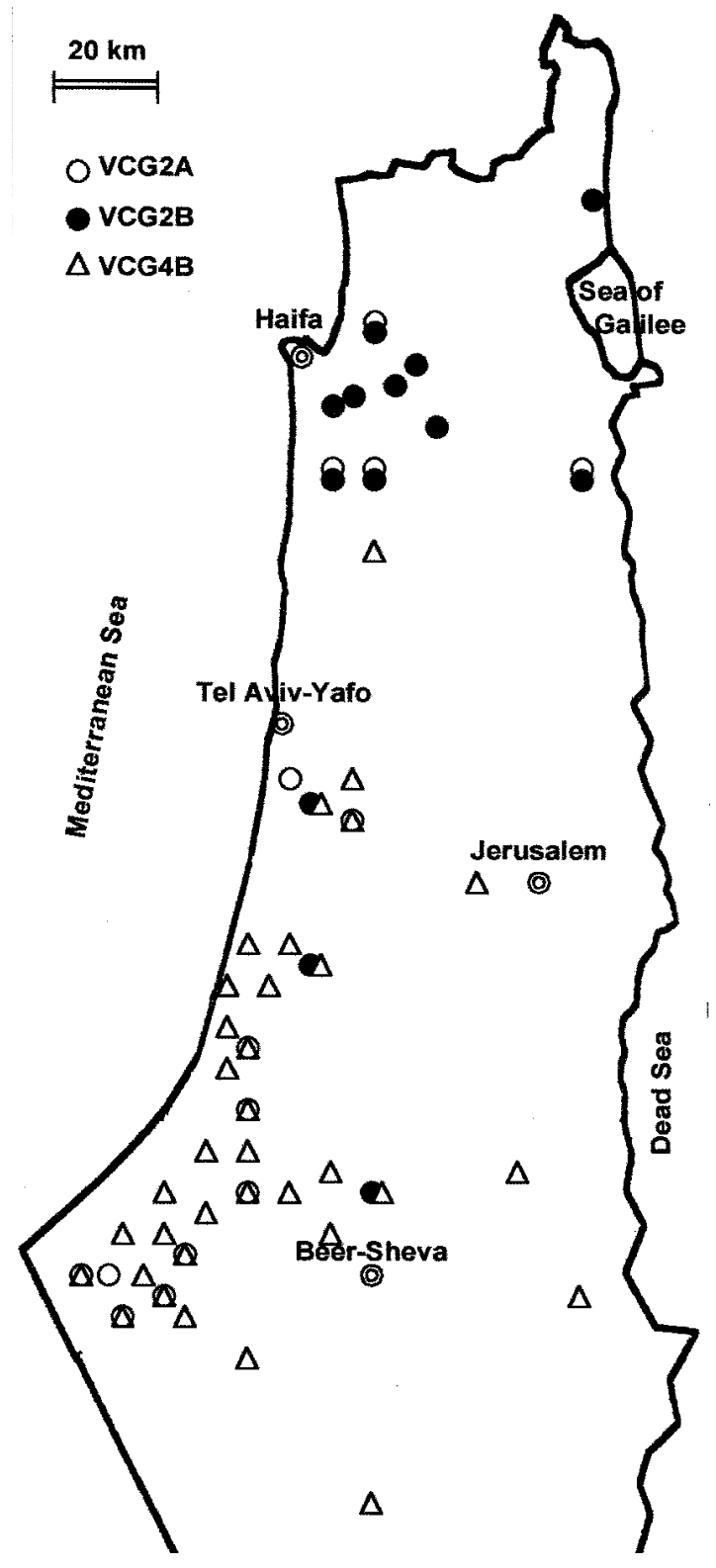

Fig. 1. Regional distribution of vegetative compatibility groups (VCGs) of Verticillium dahliae in Israel.
Assignment of strains to VCGs. A group of $46 \mathrm{~V}$. dahliae isolates from various host plants and locations was selected for initial tests. Complementary nit mutants (nitl and NitM) derived from each isolate were paired in all possible interisolate combinations (including some reciprocal pairings). Based on positive complementation reactions (Figs. 2A and 3B), three VCGs (initially designated I, II, and III) were identified among the 46 isolates tested. Complementary nit mutants that demonstrated the ability to form strong

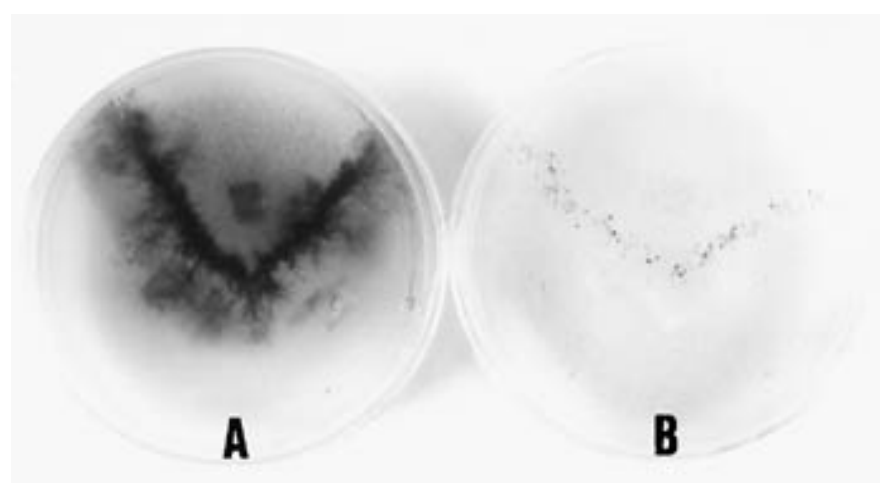

Fig. 2. Complementary heterokaryon formation between nitrate-nonutilizing mutants of Verticillium dahliae. A, Strong complementation at the contact zone between mutants belonging to vegetative compatibility group (VCG) $2 \mathrm{~B}$; and $\mathbf{B}$, weak complementation, in the form of black dots, at the contact zone between mutants belonging to VCG2A and VCG2B.

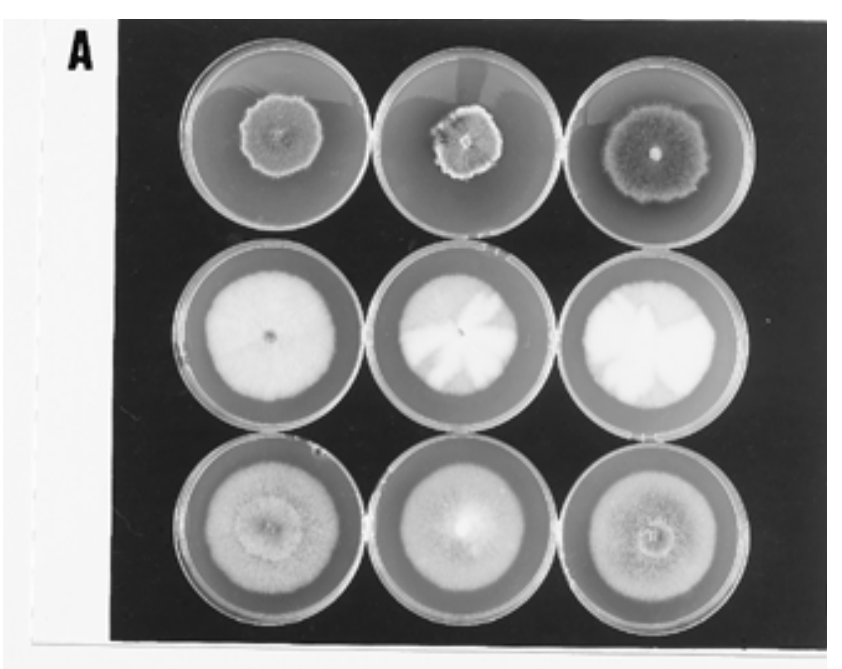

B

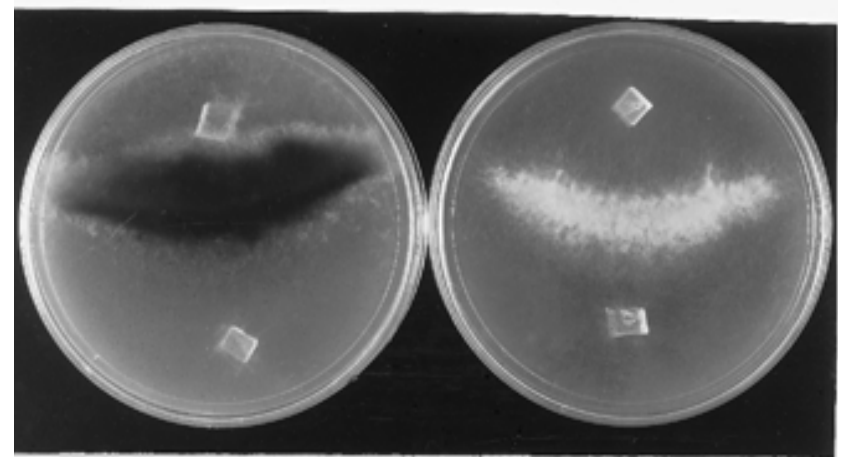

Fig. 3. Variation in colony growth and pigmentation on Czapek-Dox agar among vegetative compatibility groups (VCGs) of Verticillium dahliae. A, Three isolates from each VCG were grown in the dark at $24^{\circ} \mathrm{C}$ for 21 days (plates $9 \mathrm{~cm}$ in diameter). Top row: VCG2B isolates cot149, chr13, and ep1; middle row: VCG4B isolates pn10, pt45.4G, and tom5; and bottom row: VCG2A isolates cot150, chr9, and tom18. B, Heterokaryons of VCG2B (left) and VCG4B (right) (plates $5 \mathrm{~cm}$ in diameter, 14 days at $24^{\circ} \mathrm{C}$ ). 
heterokaryons with many other mutants were chosen as representative tester strains for each local VCG. The remaining 518 isolates were then assigned to these three VCGs based on the reaction of their nit mutants in pairings with the tester strains, and no additional VCGs were recovered. To compare the VCGs in Israel with those previously described, representative testers of the three local VCGs were paired with tester strains of the OARDC international system. Strong complementation was observed in pairings of VCG I from Israel with the international VCG2A, of VCG II with VCG2B, and of VCG III with VCG4B (Table 2). Thus, 28 isolates were assigned to VCG2A, 158 isolates to VCG2B, and 378 to VCG4B (Table 1). Partial compatibility, in the form of small dots of microsclerotia at the contact zone (Fig. 2B) was sometimes observed between testers of different VCGs (Table 2).

Regional distribution of $\boldsymbol{V}$. dahliae VCGs. Of the VCG2B isolates, $92 \%$ were recovered from the northern part of Israel, and $90 \%$ of VCG4B isolates were from the south. Some overlap was observed in the central region (Fig. 1; Table 3). Isolates of the minor group VCG2A were scattered among the two major VCGs, ranging from $8 \%$ (north) to $3 \%$ (south) of the isolates tested. VCGs essentially did not correlate with host plant of origin: all crops from the south (cotton, eggplant, peanut, potato, tomato, and weeds) were infected with VCG4B and seldom with VCG2A (eggplant, peanut, potato, and tomato), whereas all crops (except tomato) from the north (cotton, eggplant, chrysanthemum, and weeds) were infected with VCG2B and sometimes with VCG2A (cotton, eggplant, and chrysanthemum). Tomato was a notable exception: unlike the VCG4B isolates from tomato in the south, which reflected the prevailing VCG in that region, only VCG2A was recovered from tomatoes in two sites in the north (Ein Shemer and Gan Shmuel), despite the fact that cotton plants from the fields surrounding these tomato fields were infected with VCG2B.

Morphology of $\boldsymbol{V}$. dahliae strains. Morphological differences were evident between isolates from different VCGs. When grown on CDA, isolates of VCG2B formed black or dark gray colonies with little or no aerial mycelium (Fig. 3A). In contrast, most of the VCG4B isolates grew as colonies with dense aerial mycelium, were light gray or white with gray spots and sectors, and became dark gray only with age. The morphology of complementary heterokaryons in pairings of compatible nit mutants reflected the morphology of the wild-type parents: heterokaryons of VCG2B were black with abundant microsclerotia and little aerial mycelium, whereas heterokaryons of VCG4B grew slowly with more aerial mycelium and fewer, scattered microsclerotia (Fig. 3B).
All microstructures of VCG2B isolates were essentially larger than those of VCG4B. The very abundant, irregularly shaped microsclerotia of VCG2B isolates consisted of large cells, whereas the microsclerotia of VCG4B consisted of small cells that were more spherical and scattered (Fig. 4). VCG4B isolates produced abundant conidiophores that were often simple or with few phialidebearing nodes, while those of VCG2B were less abundant, larger, and with more nodes. VCG2A isolates exhibited intermediate morphology between VCG2B and VCG4B (Fig. 4).

Effect of temperature on growth of $\boldsymbol{V}$. dahliae. Of the isolates belonging to the three VCGs (5 isolates from VCG2A, 15 from VCG2B, and 15 from VCG4B) and originating from various hosts and locations, 35 were compared for growth rate on CDA at eight temperatures $\left(10\right.$ to $\left.35^{\circ} \mathrm{C}\right)$. AUGCs for a 21 -day period and temperature optimum were determined and melanization of colonies was estimated. Variation was observed among $V$. dahliae isolates and VCGs with respect to temperature growth response. VCG2A and VCG4B isolates had temperature optima of 24 to $27^{\circ} \mathrm{C}$, and VCG2A grew faster than VCG4B isolates at 18 to $27^{\circ} \mathrm{C}$ (Table 4). VCG2B isolates cumulatively showed lower and broad optimal growth temperatures, ranging from 18 to $24^{\circ} \mathrm{C}$. This VCG was heterogenic: nine isolates from cotton fields in Yizre'el Valley (Galed,

TABLE 3. Host and regional source of vegetative compatibility groups (VCGs) of Verticillium dahliae in Israel

\begin{tabular}{|c|c|c|c|c|c|c|}
\hline \multicolumn{2}{|l|}{ Source } & \multicolumn{5}{|c|}{ Number of isolates } \\
\hline Region & Host & VCG2A & VCG2B & VCG4B & $\mathrm{HSI}^{\mathrm{z}}$ & Total \\
\hline \multirow[t]{5}{*}{ North } & Cotton & 1 & 135 & 0 & 0 & 136 \\
\hline & Tomato & 9 & 0 & 0 & 0 & 9 \\
\hline & Eggplant & 3 & 4 & 0 & 0 & 7 \\
\hline & Chrysanthemum & 1 & 4 & 0 & 0 & 5 \\
\hline & Weed & 0 & 2 & 0 & 0 & 2 \\
\hline \multirow[t]{9}{*}{ Center and south } & Potato & 8 & 0 & 235 & 0 & 243 \\
\hline & Cotton & 0 & 0 & 65 & 0 & 65 \\
\hline & Tomato & 4 & 2 & 17 & 1 & 24 \\
\hline & Eggplant & 1 & 3 & 20 & 0 & 24 \\
\hline & Soil & 0 & 0 & 22 & 0 & 22 \\
\hline & Peanut & 1 & 0 & 10 & 0 & 11 \\
\hline & Pepper & 0 & 8 & 2 & 0 & 10 \\
\hline & Weeds & 0 & 0 & 6 & 0 & 6 \\
\hline & Watermelon & 0 & 0 & 1 & 0 & 1 \\
\hline Total & $\ldots$ & 28 & 158 & 378 & 1 & 565 \\
\hline
\end{tabular}

${ }^{\mathrm{z}}$ Heterokaryon self-incompatible.

TABLE 2. Complementary heterokaryon formation between representative nitrate-nonutilizing (nit) testers from Israel and the international Ohio Agricultural Research and Development Center (OARDC) reference strains of vegetative compatibility groups (VCGs) of Verticillium dahliae

\begin{tabular}{|c|c|c|c|c|c|c|c|c|c|c|}
\hline \multirow[b]{2}{*}{ nit1 Testers } & \multirow[b]{2}{*}{ VCG } & \multicolumn{9}{|c|}{ NitM testers/VCG } \\
\hline & & T9x/VCG1 & $\mathrm{PH}^{\mathrm{x}} / \mathrm{VCG} 2 \mathrm{~A}$ & ep8y/VCG I & $115^{\mathrm{x}} / \mathrm{VCG} 2 \mathrm{~B}$ & $\cot 11^{\mathrm{y} / \mathrm{VCG}} \mathrm{II}$ & $\mathrm{PCW}^{\mathrm{x}} / \mathrm{VCG} 3$ & $\mathrm{BB}^{\mathrm{x}} / \mathrm{VCG} 4 \mathrm{~A}$ & S39x/VCG4B & pt15 $/ 5^{\mathrm{y}}$ VCG III \\
\hline$T 9^{x}$ & 1 & $t^{\mathrm{z}}$ & - & - & - & $+/-$ & - & - & - & - \\
\hline $\mathrm{V} 44^{\mathrm{x}}$ & 1 & + & - & - & - & - & - & - & - & - \\
\hline $442^{x}$ & $2 \mathrm{~A}$ & - & + & + & $+/-$ & - & - & - & - & - \\
\hline $\mathrm{ph}^{\mathrm{x}}$ & $2 \mathrm{~A}$ & - & + & + & - & - & - & - & - & - \\
\hline ep5 $5^{y}$ & I & - & + & + & - & - & - & - & - & - \\
\hline tom $1^{y}$ & I & - & + & + & $+/-$ & - & - & - & $+/-$ & - \\
\hline $115^{x}$ & $2 \mathrm{~B}$ & - & - & - & + & + & - & - & - & - \\
\hline $\mathrm{MC}^{\mathrm{x}}$ & $2 \mathrm{~B}$ & - & $+1-$ & $+/-$ & + & + & - & - & - & - \\
\hline $\cot 64^{y}$ & II & $+/-$ & - & - & + & + & - & - & - & - \\
\hline $\operatorname{chr} 11^{\mathrm{y}}$ & II & - & - & - & + & + & - & - & - & - \\
\hline $70-21^{x}$ & 3 & - & - & - & - & - & + & - & - & - \\
\hline $\mathrm{PCW}^{\mathrm{x}}$ & 3 & - & - & - & - & - & + & - & - & - \\
\hline $\mathrm{BB}^{\mathrm{x}}$ & $4 \mathrm{~A}$ & - & - & - & - & $+/-$ & $+/-$ & + & - & - \\
\hline$P 105^{x}$ & $4 \mathrm{~A}$ & - & - & - & $+1-$ & - & - & + & - & - \\
\hline $\mathrm{P} 273^{\mathrm{x}}$ & 4B & - & - & - & - & - & - & - & + & + \\
\hline S39 & 4B & - & - & - & - & - & - & $+1-$ & + & + \\
\hline pt $24^{y}$ & III & - & - & - & - & - & - & $+/-$ & + & + \\
\hline pt67y & III & - & - & - & - & - & - & - & + & + \\
\hline
\end{tabular}

x OARDC reference strain (10).

y Israeli tester strain.

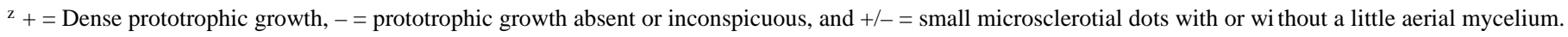


Dalia, and Ramat David) grew fastest at 18 to $21^{\circ} \mathrm{C}$, whereas six isolates from other sites (Ein Shemer, Kfar Hahoresh, and Ganey Yohanan) grew fastest at 21 to $24^{\circ} \mathrm{C}$. None of the tested $V$. dahliae isolates grew at $35^{\circ} \mathrm{C}$.

Higher temperatures $\left(27\right.$ to $\left.30^{\circ} \mathrm{C}\right)$ influenced the melanization of microsclerotia differently in the three VCGs. Melanization was completely suppressed in VCG4B strains and partially reduced in VCG2A, whereas VCG2B was, again, heterogenic. The VCG2B strains from Yizre'el Valley formed abundant black microsclerotia, with no apparent effect from the high temperatures, although the colonies became very stunted. Other VCG2B isolates formed nonmelanized colonies at 27 to $30^{\circ} \mathrm{C}$. A self-incompatible isolate from tomato had the same temperature responses as two tomato isolates belonging to VCG2A. Biomass production in liquid culture was compared at three temperatures (Table 5). VCG2B isolates (Yisre'el Valley) grew more slowly than the other two VCGs, and high temperature $\left(27^{\circ} \mathrm{C}\right)$ sharply reduced their growth.

Pathogenicity. Out of 61 isolates tested (Table 1), 60 were pathogenic to cotton and eggplant and 1 strain (chr10) was avirulent (or very slightly pathogenic; AUDPC $<2 \%$ of the maximum possible area). The 60 pathogenic isolates varied in virulence on both host plants, as evident by comparing their AUDPC values. First, isolates that incited mild symptoms on cotton (AUDPC $\leq 20 \%$ ) were defined as a nondefoliating (ND) pathotype. Other isolates caused severe foliar symptoms, stunting, and often death, but little or no defoliation of inoculated cotton plants (AUDPC $\geq 26 \%$; for most isolates, $>55 \%$ ), and were defined as a defoliating-like (DL) pathotype. Second, differential aggressiveness of the isolates on eggplant was used to further define three subgroups among the ND pathotype and two subgroups within the DL pathotype. The subgroups were statistically supported by cluster analysis. Thus, isolates of the cotton-ND pathotype that caused mild symptoms on eggplant (AUDPC $\leq 24 \%$ ) were defined as pathotype ND1, those causing moderate to strong symptoms (AUDPC 26 to $50 \%$ ) were defined as pathotype ND2, and those that caused severe symptoms (AUDPC $\geq 55 \%$ ) were defined as ND3. Similarly, within the cotton-DL pathotype, isolates that caused mild to moderate symptoms on eggplant (AUDPC $\leq 26 \%$ ) were defined as pathotype DL1 and those causing severe symptoms (AUDPC $\geq 43 \%$ ) were defined as pathotype DL2. Irrespective of their host or regional origin, all VCG2A and $86 \%$ of the VCG4B isolates (19 out of 22) were of the ND2 pathotype, inducing mild wilting in cotton but moderate to strong levels of disease in eggplant (Table 1; Fig. 5). The remaining three VCG4B isolates from cotton were highly aggressive to both differential hosts (DL2 pathotype). Greater variation in pathogenicity was found in VCG2B. In this group, all the isolates from cotton (including the less virulent cot64) originating from six sites were of the DL1 pathotype, causing severe wilt in cotton and mild to moderate symptoms in eggplant. The remaining VCG2B isolates, of noncotton origin, were highly variable and included pathotypes DL2, ND1, ND3, and one avirulent isolate.

\section{DISCUSSION}

The world population of $V$. dahliae has been found to comprise three main VCGs, designated VCG1, VCG2, and VCG4 (23); each of these VCGs has been divided into two subgroups based on quantitative differences in complementation reactions among nit mutants (12). Three VCGs were identified among 565 isolates of $V$. dahliae from Israel. VCG2 in Israel is represented by its two known subgroups (2A and 2B). Subgroups A and B of VCG2 in Israel appear to be distinct entities, distinguished by their growth rate, morphol-
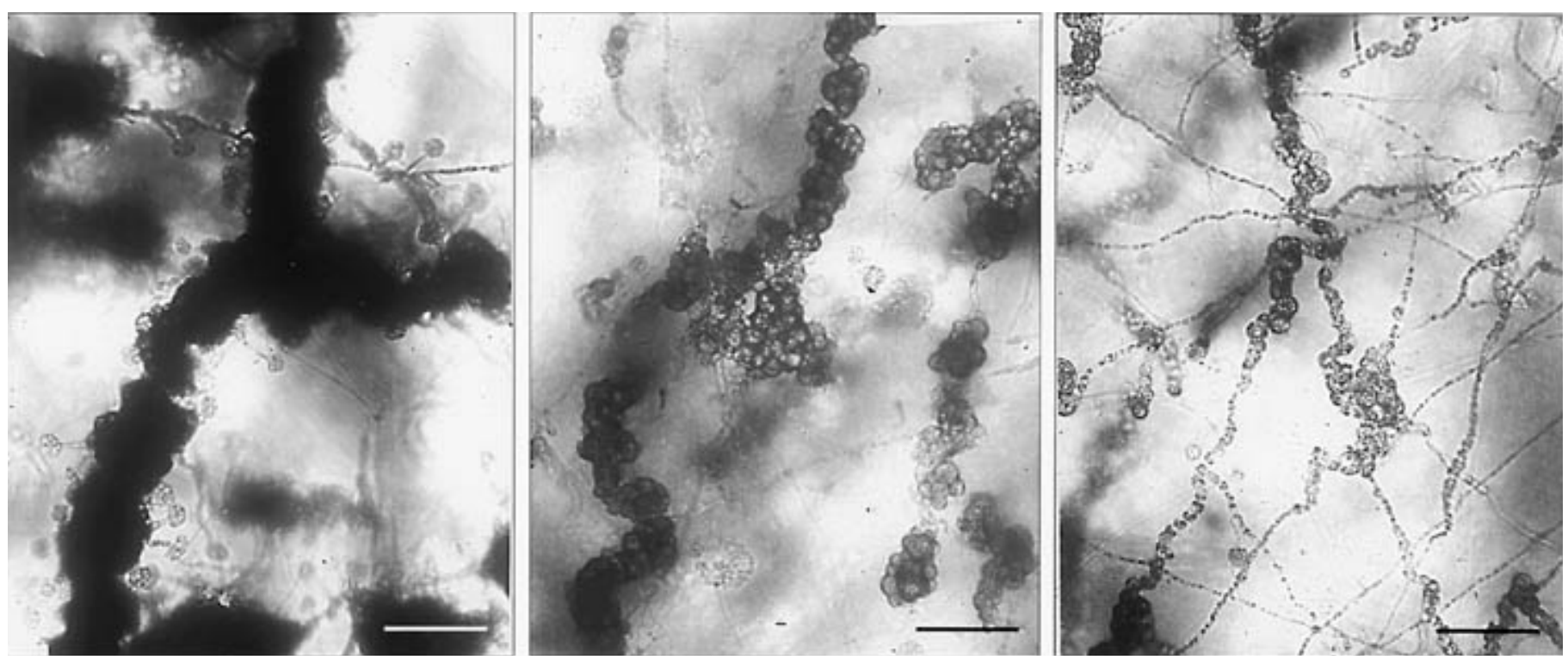

Fig. 4. Variation in microsclerotial shape and pigmentation among vegetative compatibility groups (VCGs) of Verticillium dahliae. From left to right: VCG2B, VCG2A, and VCG4B (bars $=50 \mu \mathrm{m}$, all pictures are the same magnification).

TABLE 4. Effect of temperature on radial growth of Verticillium dahliae

\begin{tabular}{|c|c|c|c|c|c|c|c|c|c|}
\hline \multirow[b]{2}{*}{$\mathrm{VCG}^{\mathrm{x}}$} & \multirow[b]{2}{*}{ No. of isolates } & \multicolumn{8}{|c|}{ Mean AUGC at each temperature ${ }^{y}$} \\
\hline & & $10^{\circ} \mathrm{C}$ & $15^{\circ} \mathrm{C}$ & $18^{\circ} \mathrm{C}$ & $21^{\circ} \mathrm{C}$ & $24^{\circ} \mathrm{C}$ & $27^{\circ} \mathrm{C}$ & $30^{\circ} \mathrm{C}$ & $35^{\circ} \mathrm{C}$ \\
\hline VCG2A & 5 & $394 \mathrm{aD}^{\mathrm{z}}$ & $663 \mathrm{aB}$ & $740 \mathrm{aB}$ & $746 \mathrm{aB}$ & $878 \mathrm{aA}$ & $896 \mathrm{aA}$ & $544 \mathrm{aC}$ & 0 \\
\hline VCG2B & 15 & $370 \mathrm{aD}$ & $591 \mathrm{aB}$ & $714 \mathrm{aA}$ & $766 \mathrm{aA}$ & $707 \mathrm{bA}$ & $624 \mathrm{bB}$ & $426 \mathrm{bC}$ & 0 \\
\hline VCG4B & 15 & $400 \mathrm{aC}$ & $571 \mathrm{aB}$ & $604 \mathrm{bB}$ & $610 \mathrm{bB}$ & $737 \mathrm{bA}$ & $729 \mathrm{bA}$ & $445 \mathrm{bC}$ & 0 \\
\hline
\end{tabular}

$\mathrm{x}$ Vegetative compatibility group.

y AUGC $=$ area under the growth curve (Czapek-Dox agar, 3 weeks).

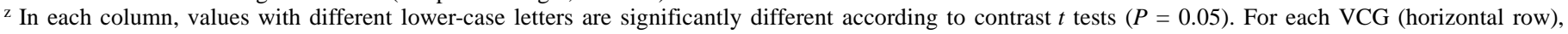
upper-case letters refer to differences between temperatures. 
ogy, pathogenicity, and regional distribution. Interactions between complementary nit mutants of VCG2A and VCG2B were absent or very weak, often only forming a line of small microsclerotial dots, with very little or no aerial mycelium. No vigorous heterokaryosis has ever been described between any testers of VCG2A and VCG2B, and combining them into VCG2 is based on frequent but weak complementation between their testers $(10,28)$. This interaction is similar to that occasionally observed between testers of different VCGs.

Most isolates from Israel belonged to VCG2B and VCG4B. These major VCGs formed two main regional populations, VCG2B in the north and VCG4B in the south, with some overlap in the center, whereas isolates of the minor group VCG2A were scattered throughout all regions among the major VCGs. In contrast, VCG2A is common in cotton fields in Spain, where no VCG2B strains have been found (14). VCGs clearly corresponded with some cultural traits and partially with pathogenicity. Using 'Acala SJ-2', two cotton pathotypes were evident: the ND pathotype caused weak to moderate symptoms, whereas the DL pathotype caused severe symptoms with little or no defoliation. The existence of cotton-defoliating (D) and -ND pathotypes in the United States and elsewhere has long been recognized $(2,3,8,26)$. Cotton isolate 115 from Syria, which had been reported as causing intermediate-type disease on 'Acala 4-42' (25), was later assigned to VCG2B (10) and now serves as one of its reference strains. The cotton-DL isolates from the north of Israel and the "intermediate" isolate 115 from neighboring Syria may be considered members of the same geographical population. In this study, the cotton-DL pathotype in Israel was represented by VCG2B cotton isolates, along with three VCG4B cotton isolates and one VCG2B chrysanthemum isolate. Irrespective of their host or regional origin, all VCG2A, most of VCG4B, and a few noncotton VCG2B isolates belonged to the cotton-ND pathotype. Using eggplant as an additional differential host allowed further strain characterization, by which each cotton pathotype was divided into subgroups. Overall, the VCG and pathotype heterogeneity of the $V$. dahliae population in Israel coexists with distinctly localized homogeneity; occurrence of more than one VCG or pathotype in the same field was rare, except for the presence of VCG2A isolates among the major VCGs. This situation should enable regional confinement of the most dangerous pathotypes. Differential susceptibility of plant species to different pathotypes (VCGs) should be considered in resistance breeding, crop rotation, and other strategies of disease management.

VCG4 is common in Verticillium wilt-affected potato fields in North America, where it consists of two or more subgroups apparently varying in pathogenicity $(3,11,12,20,27)$. $V$. dahliae is known to have been introduced with infected potato seed tubers from Europe into the Negev region (southern Israel), where it became established in many fields with expanding potato cultivation $(4,17$, 21). The presence in Israel of only subgroup VCG4B probably manifests a founder effect (18). VCG2, but not VCG4, has been reported from western and central Asia and China (3,8,10,22,25, 30 ), suggesting that VCG2 might be native (endemic) to Asia. Situ-

TABLE 5. Effect of temperature on biomass production in liquid cultures of Verticillium dahliae

\begin{tabular}{lcccc}
\hline & & \multicolumn{3}{c}{ Weight (g per flask) at each temperature } \\
\cline { 3 - 5 } VCG $^{\mathrm{y}}$ & No. of isolates & $21^{\circ} \mathrm{C}$ & $24^{\circ} \mathrm{C}$ & $27^{\circ} \mathrm{C}$ \\
\hline VCG2A & 2 & $0.43 \mathrm{aA}^{\mathrm{z}}$ & $0.50 \mathrm{aA}$ & $0.33 \mathrm{aB}$ \\
VCG2B & 5 & $0.38 \mathrm{aA}$ & $0.36 \mathrm{bA}$ & $0.16 \mathrm{bB}$ \\
VCG4B & 5 & $0.37 \mathrm{aA}$ & $0.42 \mathrm{abA}$ & $0.32 \mathrm{aA}$ \\
\hline
\end{tabular}

${ }^{\mathrm{x}}$ Vegetative compatibility group.

${ }^{y}$ Mean dry weight of mycelium. Isolates were grown in potato dextrose broth for 4 weeks.

${ }^{\mathrm{z}}$ In each column, values with different lower-case letters are significantly different according to contrast $t$ tests $(P=0.05)$. For each VCG (horizontal row), upper-case letters refer to differences between temperatures. ated since ancient times at the crossroads of the world's human civilizations, the Mediterranean Basin is infested with all known VCGs of V. dahliae: VCG1, VCG2A, and VCG4B have been found in Spain (14); VCG2, VCG3, and VCG4 have been reported from Greece (9); and now we show that VCG2A, VCG2B, and VCG4B are present in Israel.

Selective pressure exerted by the main crops in Israel apparently enhanced the establishment of two main homogeneous populations of $V$. dahliae: the DL1 pathotype of VCG2B in cotton fields in the north and the ND2 pathotype of VCG4B in potato fields (with cotton as part of the crop rotation) in the south. Noncotton or nonpotato hosts from distinct, local foci on the periphery of these regional populations provide additional, less-common pathotypes. Thus, VCG2B isolates of the ND3 pathotype were recovered from chrysanthemum and eggplant at two sites in the north and from pepper and tomato at two sites in the south. V. dahliae isolates recovered in 1992 from eggplant in Ganey Yohanan (the central region) belonged to VCG2B and were of the ND1 pathotype, whereas isolates recovered from the same site and host in 1997 belonged to VCG4B and were of the ND2 pathotype, demonstrating an apparent northbound spread of the VCG4B population. The less-common VCG2B pathotypes (DL2, ND1, and ND3) may represent the survivors of an ancient $V$. dahliae population that inhabited the region prior to the large-scale cultivation of cotton and potato. The highly aggressive DL2 pathotype includes a VCG2B isolate from chrysanthemum (north) and VCG4B isolates from cotton at two sites. The latter are the only examples of heterogeneity within VCG4B, which is predominantly of the ND2 pathotype.

Higher temperatures $\left(27\right.$ to $\left.30^{\circ} \mathrm{C}\right)$ suppressed microsclerotial melanization in VCG4B isolates commonly associated with potato, but did not suppress this process in VCG2B isolates originating from cotton. Microsclerotial melanization is an important survival factor. Potato is a temperate-climate crop, while cotton is a hotclimate crop, and the differential temperature response of the two VCGs apparently reflects an ecological adaptation of the pathogen to various environments.

So far, vegetative compatibility has been studied in five Verticillium spp. Genetic diversity in populations of the strongly pathogenic species $V$. albo-atrum and $V$. dahliae has been found to be low: two VCGs were detected among 28 isolates of $V$. albo-atrum from Europe and America (6), and three to five VCGs among several hundred $V$. dahliae isolates from numerous hosts and countries $(12,23)$. In contrast, VCG diversity in the weak plant pathogens or soil saprophytes $V$. nigrescens and $V$. tricorpus appears to

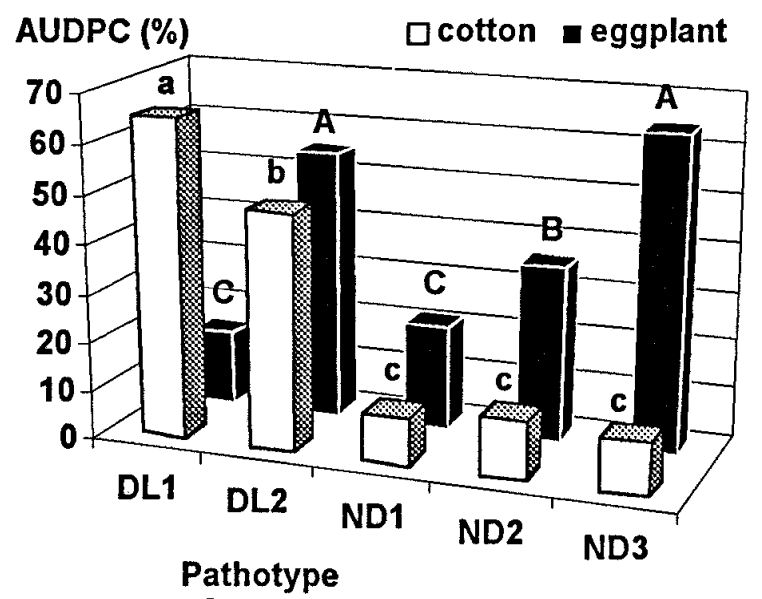

Fig. 5. Pathotypes of Verticillium dahliae defined by disease severity in cotton and eggplant. AUDPC $=$ area under disease progress curve. DL1 and DL2 = subgroups within the cotton defoliating-like (DL) pathotype; ND1, ND2, and ND3 = subgroups within the cotton-nondefoliating (ND) pathotype. For each test plant, columns designated by the same letter are not significantly different according to contrast $t$ tests at $P=0.05$. 
be higher: 9 VCGs were found among 26 isolates of $V$. tricorpus and 11 VCGs among 19 isolates of $V$. nigrescens, recovered from plants and soil in several locations in Israel (16). The entomopathogen $V$. lecanii seems to differ from both the strong and weak plant pathogens in exhibiting a high proportion of self-incompatibility and a high frequency of incompatibility between self-compatible strains (13).

This study demonstrates that different VCGs have distinct pathogenicity, macroscopic and microscopic morphology, and temperature-dependent growth rates. This finding indicates that strains belonging to the same VCG share common traits, possibly reflecting a common history. Thus, the study of VCGs in Verticillium spp. can suggest relatedness among certain strains within the pathogen population, shedding light on their evolutionary relationship and, often, predicting their pathogenic potential.

\section{ACKNOWLEDGMENTS}

This research was supported, in part, by a fellowship (for N. Korolev) from the Israeli Ministry of Immigration, by the United States-Israel Binational Agricultural Research and Development Fund (BARD Project US-2659-95), by the research fund of the Chief Scientist of Israel Ministry of Agriculture, and by the Israel Cotton Production and Marketing Board. Contribution 508/99 from the ARO Institute of Plant Protection. We thank R. C. Rowe for providing the international reference strains of the Verticillium dahliae VCGs; L. Tsror for isolates of V. dahliae; G. Fishler and Y. Peretz for long-term cooperation; and E. Dubitzki, G. Elal, A. Gamliel, A. Grinstein, D. Levy, Y. Sachs, D. Sadeh, and T. Sando for assistance in collecting diseased plants.

\section{LITERATURE CITED}

1. Bao, J. R., Katan, J., Shabi, E., and Katan, T. 1998. Vegetative-compatibility groups in Verticillium dahliae from Israel. Eur. J. Plant Pathol. 104: 263-269.

2. Bejarano-Alcazar, J., Melero-Vera, J. M., Blanco-Lopez, M. A., and Jimenez-Diaz, R. M. 1995. Influence of inoculum density of defoliating and nondefoliating pathotypes of Verticillium dahliae on epidemics of Verticillium wilt of cotton in Southern Spain. Phytopathology 85:1474-1481.

3. Bell, A. A. 1994. Mechanisms of disease resistance in Gossypium species and variation in Verticillium dahliae. Pages 225-235 in: Proc. World Cotton Res. Conf. 1. G. A. Constable and N. W. Forrester, eds. CSIRO, Melbourne, Australia.

4. Ben-Yephet, Y., and Szmulewich, Y. 1985. Inoculum levels of Verticillium dahliae in the soils of the hot semi-arid region of Israel. Phytoparasitica 13:193-200.

5. Campbell, C. L., and Madden, L. V. 1990. Introduction to Plant Disease Epidemiology. John Wiley \& Sons, Inc., New York.

6. Correll, J. C., Gordon, T. R., and McCain, A. H. 1988. Vegetative compatibility and pathogenicity of Verticillium albo-atrum. Phytopathology 78:1017-1021.

7. Correll, J. C., Klittich, C. J. R., and Leslie, J. F. 1987. Nitrate nonutilizing mutants of Fusarium oxysporum and their use in vegetative compatibility tests. Phytopathology 77:1640-1646.

8. Daayf, F., Nicole, M., and Geiger, J. P. 1995. Differentiation of Verticillium dahliae populations on the basis of vegetative compatibility and pathogenicity on cotton. Eur. J. Plant Pathol. 101:69-79.

9. Elena, K., and Paplomatas, E. J. 1998. Vegetative compatibility groups within Verticillium dahliae isolates from different hosts in Greece. Plant Pathol. 47:635-640.
10. Joaquim, T. R., and Rowe, R. C. 1990. Reassessment of vegetative compatibility relationships among strains of Verticillium dahliae using nitrate-nonutilizing mutants. Phytopathology 80:1160-1166.

11. Joaquim, T. R., and Rowe, R. C. 1991. Vegetative compatibility and virulence of strains of Verticillium dahliae from soil and potato plants. Phytopathology 81:552-558.

12. Katan, T. 2000. Vegetative compatibility in populations of VerticilliumAn overview. Pages 77-94 in: Advances in Verticillium Research and Disease Management. E. Tjamos, R. C. Rowe, J. B. Heale, and D. Fravel, eds. The American Phytopathological Soceity, St. Paul, MN.

13. Korolev, N., and Gindin, G. 1999. Vegetative compatibility in the entomopathogen Verticillium lecanii. Mycol. Res. 103:833-840.

14. Korolev, N., Jimenez-Diaz, R., Katan, J., Perez-Artes, E., Garcia-Pedrajas, M., Bejarano-Alcazar, J., Rodriguez-Jurado, D., and Katan, T. 2000. Comparative study of vegetative compatibility and pathogenicity among cotton isolates of Verticillium dahliae from Spain and Israel. Pages 117-119 in: Advances in Verticillium Research and Disease Management. E. Tjamos, R. C. Rowe, J. B. Heale, and D. Fravel, eds. The American Phytopathological Society, St. Paul, MN.

15. Korolev, N., and Katan, T. 1997. Improved medium for selecting nitrate nonutilizing (nit) mutants of Verticillium dahliae. Phytopathology 87: 1067-1070.

16. Korolev, N., and Katan, T. 1999. Vegetative compatibility grouping in Verticillium nigrescens and V. tricorpus. Mycol. Res. 103:65-76.

17. Krikun, J., and Orion, D. 1979. Verticillium wilt of potato: Importance and control. Phytoparasitica 7:107-116.

18. McDonald, B. 1997. The population genetics of fungi: Tools and techniques. Phytopathology 87:448-453.

19. Nachmias, A., Kaufman, Z., Livescu, L., Tsror, L., Meiri, A., and Caligari, P. D. S. 1993. Effects of salinity and its interaction with disease incidence on potato grown in hot climates. Phytoparasitica 21:245-255.

20. Omer, M. A., and Rowe, R. C. 1998. Virulence of two Verticillium dahliae pathotypes isolated from potato seed tubers. (Abstr.) Phytopathology 88 (suppl.):S69.

21. Pegg, G. F. 1974. Verticillium diseases. Rev. Plant Pathol. 53:157-182.

22. Portenko, L. G., and Akimov, G. I. 1997. Vegetative compatibility among Verticillium dahliae populations of cotton-growing regions of the Middle Asia. (Abstr.) Page 93 in: Proc. 7th Int. Verticillium Symp.

23. Rowe, R. C. 1995. Recent progress in understanding relationships between Verticillium species and subspecific groups. Phytoparasitica 23: 31-38.

24. Schnathorst, W. C.1981. Life cycle and epidemiology of Verticillium. Pages 113-144 in: Fungal Wilt Diseases of Plants. M. E. Mace, A. A. Bell, and C. H. Beckman, eds. Academic Press, New York.

25. Schnathorst, W. C., and Fogle, D. 1976. Comparative virulence and other characteristics of Verticillium dahliae isolates from cotton plants in the United States, USSR, Syria and Iran. Pages 22-23 in: Proc. Beltwide Cotton Prod. Res. Conf. Cotton Disease Council, Memphis,TN.

26. Schnathorst, W. C., and Mathre, D. E. 1966. Host range and differentiation of a severe form of Verticillium albo-atrum in cotton. Phytopathology 56:1155-1161.

27. Strausbaugh, C. A. 1993. Assessment of vegetative compatibility and virulence of Verticillium dahliae isolates from Idaho potatoes and tester strains. Phytopathology 83:1253-1258.

28. Strausbaugh, C. A., Schroth, M. N., Weinhold, A. R., and Hancock, J. G. 1992. Assessment of vegetative compatibility of Verticillium dahliae tester strains and isolates from California potatoes. Phytopathology 82: 61-68.

29. Tsror, L., Erlich, O., Amitai, S., and Hazanovsky, M. 1998. Verticillium wilt of paprika caused by a highly virulent isolate of Verticillium dahliae. Plant Dis. 82:437-439.

30. Xia, Z., Achar, P. N., and Gu, B. 1998. Vegetative compatibility grouping of Verticillium dahliae from cotton in mainland China. Eur. J. Plant Pathol. 104:871-876. 